\title{
Neoadjuvant chemotherapy adaptation and serial MRI response monitoring in ER-positive HER2-negative breast cancer
}

L S Rigter ${ }^{1}$, C E Loo ${ }^{2}$, S C Linn ${ }^{1}$, G S Sonke ${ }^{1}$, E van Werkhoven ${ }^{3}$, E H Lips ${ }^{4,5}$, H A Warnars ${ }^{2}$, P K Doll ${ }^{2}$, A Bruining ${ }^{2}$, I A Mandjes ${ }^{6}$, M J Vrancken Peeters ${ }^{7}$, J Wesseling ${ }^{5}$, K G Gilhuijs ${ }^{2,8}$ and S Rodenhuis ${ }^{*}, 1$

${ }^{1}$ Department of Medical Oncology, The Netherlands Cancer Institute, Plesmanlaan 121, Amsterdam 1066, The Netherlands; ${ }^{2}$ Department of Radiology, The Netherlands Cancer Institute, Amsterdam, The Netherlands; ${ }^{3}$ Department of Statistics, The Netherlands Cancer Institute, Amsterdam, The Netherlands; ${ }^{4}$ Department of Molecular Pathology, The Netherlands Cancer Institute, Amsterdam, The Netherlands; ${ }^{5}$ Department of Pathology, The Netherlands Cancer Institute, Amsterdam, The Netherlands; ${ }^{6}$ Department of Data Center, The Netherlands Cancer Institute, Amsterdam, The Netherlands; ${ }^{7}$ Department of Surgical Oncology, The Netherlands Cancer Institute, Amsterdam, The Netherlands and ${ }^{8}$ Department of Radiology, University Medical Centre Utrecht, Utrecht, The Netherlands

Background: Changing the neoadjuvant chemotherapy regimen in insufficiently responding breast cancer is not a standard policy. We analysed a series of patients with 'luminal'-type breast cancer in whom the second half of neoadjuvant chemotherapy was selected based on the response to the first half.

Methods: Patients with oestrogen receptor-positive $(E R+)$ human epidermal growth factor receptor 2-negative (HER2 -) breast cancer received three courses of neoadjuvant dose-dense doxorubicin and cyclophosphamide (ddAC). Three further courses of ddAC were administered in case of a 'favourable response' on the interim magnetic resonance imaging (MRI) and a switch to docetaxel and capecitabine (DC) was made in case of an 'unfavourable response', using previously published response criteria. The efficacy of this approach was evaluated by tumour size reductions on serial contrast-enhanced MRI, pathologic response and relapse-free survival.

Results: Two hundred and forty-six patients received three courses of ddAC. One hundred and sixty-four patients (67\%) had a favourable response at the interim MRI, with a mean tumour size reduction of 31\% after the first three courses and $34 \%$ after the second three courses. Patients with unfavourable responsive tumours had a mean tumour size reduction of $12 \%$ after three courses and received three courses of DC rather than ddAC. This led to a mean shrinkage of $27 \%$.

Conclusion: The tumour size reduction of initially less responsive tumours after treatment adaptation adds further evidence that a response-adapted strategy may enhance the efficacy of neoadjuvant chemotherapy.

Neoadjuvant chemotherapy has been shown to be equally effective as adjuvant chemotherapy in terms of breast cancer survival (Mauri et al, 2005), when the preoperative regimen is the same as the postoperative adjuvant regimen. It is tempting to assume that neoadjuvant chemotherapy could be superior to adjuvant chemotherapy if the regimen were adapted to the response of the primary tumour. If the tumour fails to decrease in size, a switch could be made to a (presumably) non-cross-resistant regimen that could be more effective than the first one. This simple concept has not been adopted in practice, perhaps because early experience 
suggested that a change of chemotherapy should be made anyway (Smith et al, 2002) and perhaps because response monitoring is difficult and suitable criteria for a satisfactory response after the first course(s) are not available. More recently, however, a report from the German Breast Group suggested that response-adapted chemotherapy could be effective: breast cancer patients who received vinorelbine and capecitabine after failure of a combination of docetaxel, doxorubicin and cyclophosphamide (TAC) had a better survival than those who continued on TAC (von Minckwitz et al, 2013).

Response monitoring can be performed by means of physical examination, by sonographic measurement or by mammographic measurement (Rosen et al, 2003; Prati et al, 2009). Contrastenhanced magnetic resonance imaging (MRI) is generally regarded as the most accurate imaging method for invasive breast cancer (Yeh et al, 2005; Shin et al, 2011) and is increasingly used for the evaluation of neoadjuvant chemotherapy response. Our group has previously published criteria for a satisfactory MRI response during chemotherapy (Loo et al, 2008). We have recently shown that these criteria are strongly predictive for a pathologic complete remission ( $\mathrm{pCR}$ ) in triple-negative disease, but are less accurate in tumours that are oestrogen receptor-positive $(\mathrm{ER}+)$ and human epidermal growth factor receptor 2-negative (HER2 - ) (Loo et al, 2011). The latter group of patients frequently receives preoperative chemotherapy with the objective to decrease tumour size to facilitate breast-conserving therapy. A pCR, however, is only rarely achieved. Consequently, the pCR is not an ideal measure of tumour response and it has recently been shown that it is of no prognostic value in lower-grade ER + HER2 - ('luminal A') disease (von Minckwitz et al, 2012). We have proposed a simple measure of downstaging, the 'Neoadjuvant Response Index', to better quantify the responsiveness of this subgroup to neoadjuvant chemotherapy (Rodenhuis et al, 2010). Whether this index is predictive of recurrence-free survival is still under investigation and awaits longer follow-up and/or independent confirmation.

Here, we review the data of a series of consecutive patients with ER + HER2 - breast cancer in our single-institution neoadjuvant chemotherapy program, who were started on neoadjuvant chemotherapy with dose-dense doxorubicin and cyclophosphamide (ddAC). The program serves to develop biomarkers for response prediction and to refine techniques for response monitoring. The objective of this analysis was to evaluate a consecutive series of participating patients with high-risk ER + HER2 - breast cancer who received response-adapted neoadjuvant chemotherapy and to help prepare future controlled studies to further develop such a strategy.

Specifically, we wished to investigate the degree of tumour shrinkage after a change of chemotherapy regimen because of an unsatisfactory response to ddAC.

\section{MATERIALS AND METHODS}

Patients. Patients between 18 and 70 years of age were included when invasive ER + HER2 - breast cancer was present, that was either $>3 \mathrm{~cm}$ in size or was associated with at least one tumourpositive axillary lymph node. Both tumours of the surrogate intrinsic subtypes luminal $A$ and luminal $B$ were offered neoadjuvant chemotherapy; we have shown previously that major response can be observed in luminal A tumours as well (Lips et al, 2012). When bilateral cancer was found, the larger tumour was used for this analysis. A previous diagnosis of invasive breast cancer was a reason for exclusion. Only patients who received initial chemotherapy consisting of ddAC were included.

All patients either took part in a single-institution clinical trial, which was approved by the ethical committee, or were treated off study according to the standard arm of the trial. All patients included in the clinical trial gave written informed consent, all other patients consented orally.

Treatment. All patients began neoadjuvant chemotherapy with three courses of ddAC (doxorubicin $60 \mathrm{mg} \mathrm{m}^{-2}$ and cyclophosphamide $600 \mathrm{mg} \mathrm{m}^{-2}$ on day 1 , every 14 days, with PEG-filgrastim on day 2) between 2004 and 2012. Three courses of docetaxel and capecitabine (DC, docetaxel $75 \mathrm{mg} \mathrm{m}^{-2}$ on day 1, every 21 days and capecitabine $2 \times 1000 \mathrm{mg} \mathrm{m}^{-2}$ on days $1-14$ ) were administered when an 'unfavourable response' was detected by MRI evaluation after the three initial courses. When a 'favourable response' was achieved, three further courses of ddAC were administered.

Following chemotherapy, all patients underwent surgery (either mastectomy or breast-conserving therapy), radiation therapy when indicated and at least 5 years of endocrine treatment according to national guidelines.

MRI technique and assessment. Contrast-enhanced MRI monitoring was performed as described previously (Loo et al, $2008,2011)$. Briefly, images were acquired with the patient in prone orientation using a dedicated breast coil and with both breasts imaged. The standard dynamic protocol started with an unenhanced coronal three-dimensional fast-field echo (thrive) T1-weighted sequence. A bolus $(14 \mathrm{ml})$ of gadolinium-containing contrast $\left(0.1 \mathrm{mmol} \mathrm{kg}^{-1}\right)$ was administered intravenously at $3 \mathrm{ml} \mathrm{s}^{-1}$ using a power injector followed by a bolus of $30 \mathrm{ml}$ of saline solution. Subsequently, dynamic imaging was performed in five consecutive series at 90-s intervals. Temporal and morphologic characteristics of contrast uptake were assessed as described previously.

Response criteria: MRI. Contrast-enhanced MRI was performed before chemotherapy (baseline), after three courses of chemotherapy (interim) and after six courses of chemotherapy (postchemotherapy). The criteria for either a 'favourable' or an 'unfavourable' response were applied as published (Loo et al, 2008). Reduction of more than $25 \%$ in the largest diameter of the tumour at late enhancement on the interim MRI relative to the baseline MRI was regarded as a 'favourable' response. All other responses were classified as 'unfavourable'. The largest tumour diameter was assessed in three reformatted planes by one of four experienced breast $\mathrm{MR}$ radiologists (CL, HW, PD, AB). The initial enhancement and late enhancement were individually measured. The total area of breast tissue including non-enhancing tissue was used in case of multifocal disease or a diffuse (non-mass) tumour. The reduction in largest tumour diameter at initial enhancement was calculated by dividing the difference in tumour diameter between interim and baseline MRI by the tumour diameter at baseline MRI.

Response criteria: microscopy. Three common definitions of pCR were used: no residual invasive tumour in the breast (ypT0/is $\mathrm{ypN} 0 /+$ ); no residual invasive tumour in both the breast and the lymph nodes (ypT0/is ypN0); and the absence of any tumour (invasive or non-invasive) in breast and lymph nodes (ypT0 ypN0).

Survival analysis. Relapse-free survival (RFS) was also used as an end point and was defined as the length of time from the first treatment to local or distant relapse or death by any cause. Ipsilateral ductal carcinoma in situ, contralateral breast cancer and second primary invasive cancer were not regarded as 'events' for this analysis.

Staging. As substantially more clinical lymph node staging information was available than is used for the clinical N-staging according to the UICC, we adapted the N-stage to match a more detailed method. A negative sentinel node was assigned stage $\mathrm{cNa}$; positive sentinel node stage $\mathrm{cNb}$; non-palpable and fine-needle 
aspiration (FNA)-positive node stage $\mathrm{cNc}$; axillary palpable and FNA-positive stage $\mathrm{cNd}$; and periclavicular and FNA-positive stage $\mathrm{cNe}$.

Immunohistochemistry. On average, three ultrasound-guided pre-treatment core biopsies of the primary tumour were taken using a $14 \mathrm{G}$ core needle, after which two biopsies were snap-frozen in liquid nitrogen and stored at $-80^{\circ} \mathrm{C}$ for molecular analysis and one biopsy was formalin-fixed and embedded in paraffin for classification and immunohistochemistry (IHC). Oestrogen receptor and progesterone receptor (PR) were evaluated as positive when at least $10 \%$ of tumour cells showed nuclear staining. Human epidermal growth factor receptor 2 status was scored negative when IHC showed no or only weak or incomplete membranous staining (score 0 or $1+$ ) or chromogenic in situ hybridisation revealed no amplification after moderate membrane staining (score $2+$ ). Ki-67 was used for assessment of proliferation status and to assess surrogate intrinsic subtypes (Goldhirsch et al, 2011). The Mib-1 antibody was used for determination of Ki-67 status, using the cutoff point of $14 \%$ of positive staining. This cutoff point was determined as it yielded the best separation of luminal $\mathrm{A}$ and luminal B tumours, as defined by the PAM50 algorithm in the subgroup of tumours of which mRNA expression arrays were available. Ki-67 cutoff point was determined by preparing ROC curves comparing results with PAM50 intrinsic subtypes (Parker et al, 2009). As Ki-67 status was not determined for all tumours, histological grade (when available) was also used for a second definition of 'surrogate intrinsic subtypes' (Goldhirsch et al, 2011). Histological grade was determined using the Elston and Ellis method (Ellis et al, 1992). High endocrine responsiveness was defined as at least $50 \%$ of the tumour cell nuclei stained positive, for both ER and PR, in the absence of HER2 amplification (Colleoni et al, 2009). Surrogate definitions of intrinsic subtypes were used, based on IHC. 'Luminal A' tumours are ER + and/or $\mathrm{PR}+$, HER $2-$ and have $<14 \%$ of the nuclei staining positive for Ki-67 (or, when based on histological grade, grade 1 or 2). 'Luminal B (HER2 - )' tumours are ER + and/or PR +, HER2 and $\mathrm{Ki}-67 \geqslant 14 \%$ (or histological grade 3 ) (Goldhirsch et al, 2011).

Statistics. The software program SPSS version 20 (SPSS Inc., Chicago, IL, USA) was used for all analyses. For the assessment of associations between characteristics and MRI response or pCR, the Fisher's exact test was used. Mann-Whitney $U$-tests were used for the comparison of MRI measured tumour size reduction percentage and potential predictive markers. Relapse-free interval analysis was performed using Kaplan-Meier curves and Cox regression analysis.

\section{RESULTS}

Patients. A total of 309 patients with ER + HER2 - breast cancer began neoadjuvant chemotherapy with three courses of ddAC between October 2004 and March 2012 (Table 1). Of these, 292 patients had an MRI after the first three courses and were evaluable for response. The second chemotherapy regimen was selected according to protocol in 275 patients. For 246 patients, all three serial MRI measurements of the initial enhancement diameter were reviewed (Table 1 and Figure 1). A total of 7 (2.8\%) of all 246 patients achieved a pCR (ypT0 ypN0) after six courses. Additional (postoperative) adjuvant chemotherapy was administered in 43 (17\%) out of 246 patients (14 unfavourable responders, 29 favourable responders) and consisted usually of taxane treatment (12 weekly administrations of paclitaxel, $80 \mathrm{mg} \mathrm{m}^{-2}$ when the patient was taxane-naive). The median follow-up was 35 months with a lead follow-up of 98 months. The 5-year relapsefree survival for all 246 patients was $87 \%$, with an overall 5-year survival of $96 \%$.

\section{Table 1. Patient and tumour characteristics}

\begin{tabular}{|l|c|}
\hline Number of patients & 246 \\
\hline Median age, (range) in years & $48(18-68)$ \\
\hline Tumour stage \\
\hline CT1 & 21 \\
CT2 & 91 \\
CT3 & 43 \\
CT4 & 9 \\
\hline
\end{tabular}

\section{$\mathrm{N}$-stage}

\section{cNa (negative)}

cNb (FNA negative, sentinel node positive)

cNc (ultrasound-guided FNA positive)

cNd (palpable nodes, FNA positive)

cNe (FNA-positive periclavicular node(s))

\section{Histological grade}

1

2

3

$\mathrm{NS}^{\mathrm{a}}$

14

95

30

107

\section{Histology}

\section{Ductal}

Lobular

Ductal/lobular

Other

190

33

6

17

ER (\%)

\section{0-49}

50-100

positive $^{b}$

\section{PR (\%)}

$$
\text { 0-49 }
$$

50-100

ND (no PR (\%) available)

Surrogate intrinsic subtype: based on Ki-67

Luminal A (ER/PR + ; HER2 - ; Ki-67 low)

Luminal B/HER2 - (ER/PR + ; HER2 - ; Ki-67 high)

ND (no Ki-67 available)

\section{Surrogate intrinsic subtype: based on histological grade}

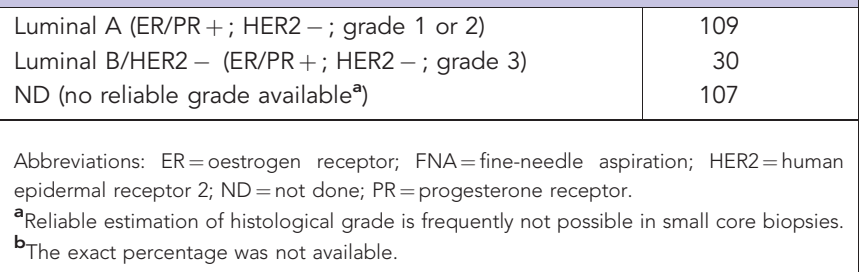

Patient and tumour characteristics and interim MRI response. All three MRI evaluations were available for 246 patients. One hundred and sixty-four patients (67\%) achieved a favourable response as determined by the MRI criteria (over 25\% decrease in the largest tumour diameter of late enhancement) and 82 patients (33\%) had an unfavourable response after three courses of ddAC.

A favourable response was more often seen in patients with positive $\mathrm{N}$-stage $(P=0.011)$, but it was not more frequent in incompletely endocrine-responsive tumours or in tumours of higher grade or with higher Ki-67 (Table 2). 


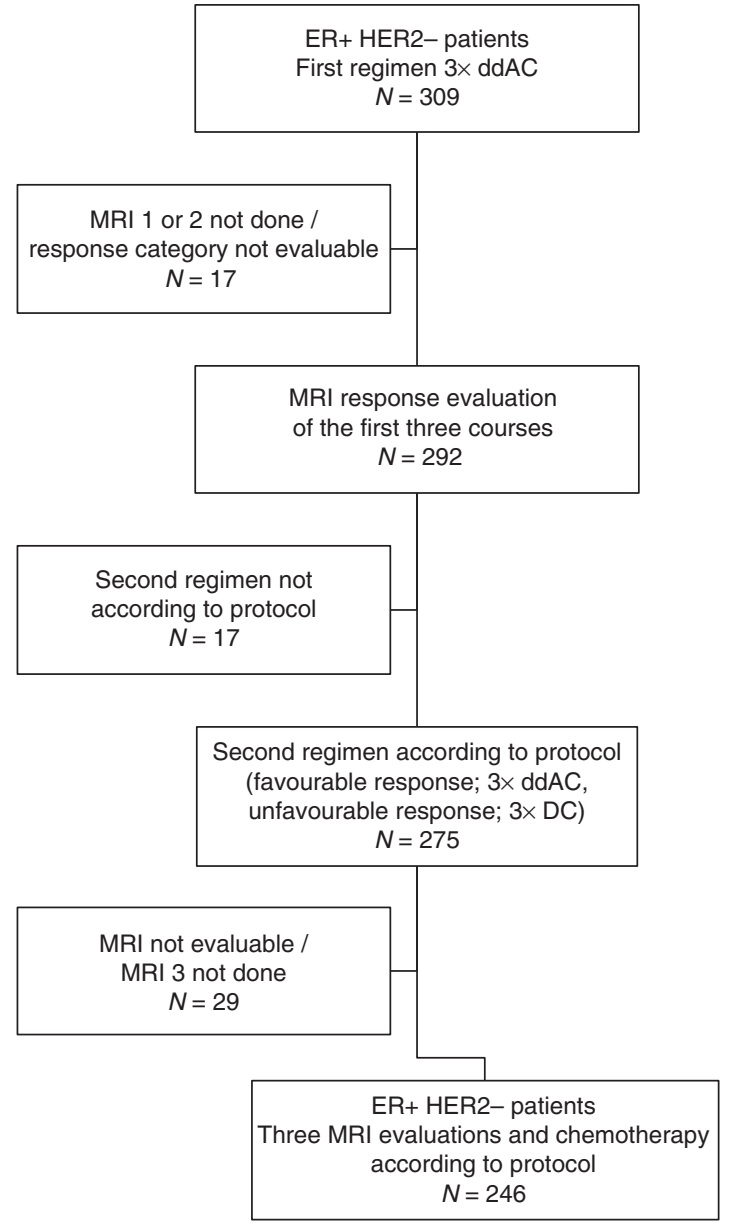

Figure 1. CONSORT diagram showing MRI evaluations.

Interim MRI response and outcome. In 246 patients, 18 pathologic complete remissions of the breast (7\%) were observed, 7 complete remissions of both breast and axilla (3\%) and 4 complete remissions of breast and axilla in the absence of residual carcinoma in situ (2\%). A favourable MRI response was associated with a higher $\mathrm{pCR}$ rate than an unfavourable response $(P=0.04$ for ypT0/is ypNo/ + ), but the numbers were very small. Eight relapse events $(10 \%)$ occurred in the 82 unfavourably responding patients and 16 relapses (10\%) in the 164 favourably responding ones (NS, $P=0.99$ ) (Table 3).

Interim MRI response and serial MRI evaluation. The first three courses of ddAC resulted in a mean tumour size reduction of $31 \%$ in 164 favourable response patients, which was followed by three more courses of ddAC. In 82 unfavourable response patients who had achieved a mean tumour size reduction of only $12 \%$, a switch to the DC regimen was made.

The overall radiologic tumour size reduction percentage after six courses of chemotherapy was higher in patients who had achieved a favourable response on the interim MRI (56\%) than in patients who had not achieved a favourable response (35\%). The fractional reduction in tumour size as measured by MRI over the second set of three courses, however, was similar for both the initially favourable $(34 \%)$ and the initially unfavourable $(27 \%)$ responders (Table 4 and Figure 2). Seven favourably responding tumours had a radiologic CR on their second MRI, which - by definition resulted in a tumour size reduction of $0 \%$ after the second course of ddAC.

Patient and tumour characteristics and outcome. The predictive and prognostic impact of tumour characteristics was analysed with
Table 2. Patient and tumour characteristics and interim MRI response (after three courses of neoadjuvant chemotherapy)

\begin{tabular}{|c|c|c|c|}
\hline Characteristic & $\begin{array}{c}\text { MRI } \\
\text { favourable } \\
\text { response } \\
(\mathbf{N}=164) \\
N(\%)\end{array}$ & $\begin{array}{c}\text { MRI } \\
\text { unfavourable } \\
\text { response } \\
(\mathbf{N}=\mathbf{8 2}) \\
\mathbf{N}(\%)\end{array}$ & $\boldsymbol{P}$-value \\
\hline T-stage & & & 0.885 \\
\hline $\begin{array}{l}\text { cT1/cT2 } \\
\text { cT3/cT4 }\end{array}$ & $\begin{aligned} 112(68) \\
52(32)\end{aligned}$ & $\begin{array}{l}57(70) \\
25(31)\end{array}$ & \\
\hline $\mathrm{N}$-stage & & & 0.011 \\
\hline $\begin{array}{l}\mathrm{cN} \text { negative } \\
\mathrm{cN} \text { positive }\end{array}$ & $\begin{array}{r}25(15) \\
139(85)\end{array}$ & $\begin{array}{l}24(29) \\
58(71)\end{array}$ & \\
\hline Histology & & & 0.112 \\
\hline $\begin{array}{l}\text { Lobular } \\
\text { Ductal } \\
\text { Other }\end{array}$ & $\begin{array}{c}26(18) \\
120(82) \\
18\end{array}$ & $\begin{array}{c}7 \text { (9) } \\
70 \text { (91) } \\
5\end{array}$ & \\
\hline Age (years) & & & 0.412 \\
\hline $\begin{array}{l}<50 \\
\geqslant 50\end{array}$ & $\begin{array}{r}101(62) \\
63(38)\end{array}$ & $\begin{array}{l}46((56) \\
36(44)\end{array}$ & \\
\hline Endocrine responsiveness & & & 0.585 \\
\hline $\begin{array}{l}\text { Incomplete (ER or PR <50\%) } \\
\text { High (ER and PR } \geqslant 50 \% \text { ) } \\
\text { ND }\end{array}$ & $\begin{array}{c}74(47) \\
83(53) \\
7\end{array}$ & $\begin{array}{c}35(43) \\
46(57) \\
1\end{array}$ & \\
\hline $\begin{array}{l}\text { Surrogate intrinsic subtype } \\
\text { (Ki-67) }\end{array}$ & & & 0.510 \\
\hline $\begin{array}{l}\text { Luminal } A(<14) \\
\text { Luminal } B(\geqslant 14) \\
\text { ND }\end{array}$ & $\begin{array}{l}82(66) \\
42(34) \\
40\end{array}$ & $\begin{array}{c}46(72) \\
18(28) \\
18\end{array}$ & \\
\hline $\begin{array}{l}\text { Surrogate intrinsic subtype } \\
\text { (grade) }\end{array}$ & & & 1.0 \\
\hline $\begin{array}{l}\text { Luminal A (1/2) } \\
\text { Luminal B (3) } \\
\text { ND }\end{array}$ & $\begin{array}{l}73(79) \\
20(22) \\
71\end{array}$ & $\begin{array}{c}36(78) \\
10(22) \\
36\end{array}$ & \\
\hline $\begin{array}{l}\text { Abbreviations: } \quad E R=\text { oestrogen } \\
N D=\text { not done; } P R=\text { progesteror } \\
\text { enhancement diameter on the seco } \\
\text { response (Loo et al, 2008). }\end{array}$ & $\begin{array}{l}\text { ptor; } \quad M R I= \\
\text { eptor. A re } \\
\text { trast-enhanc }\end{array}$ & $\begin{array}{l}\text { etic resonance } \\
\text { of over } 25 \% \text { was regarded as a }\end{array}$ & $\begin{array}{l}\text { imaging; } \\
\text { the late } \\
\text { avourable }\end{array}$ \\
\hline
\end{tabular}

Table 3. Association of interim MRI response after three courses of neoadjuvant chemotherapy with outcome measures

\begin{tabular}{|l|c|c|c|c|c|}
\hline $\begin{array}{l}\text { MRI response } \\
\text { category }\end{array}$ & $\mathbf{N}$ & $\begin{array}{c}\text { ypT0/is } \\
\text { ypN0/+ }\end{array}$ & $\begin{array}{c}\text { ypT0/is } \\
\text { ypN0 }\end{array}$ & $\begin{array}{c}\text { ypT0 } \\
\text { ypN0 }\end{array}$ & $\begin{array}{c}\text { RFS hazard } \\
\text { ratio (95\% CI) }\end{array}$ \\
\hline Favourable & 164 & 10 & 4 & 2 & Ref. \\
\hline Unfavourable & 82 & 2 & 1 & 1 & $\begin{array}{c}0.995 \\
(0.42-2.33)\end{array}$ \\
\hline -value $^{\text {a }}$ & & 0.04 & 0.43 & 1.0 & 0.99 \\
\hline
\end{tabular}

Abbreviations: $\quad \mathrm{Cl}=$ confidence interval; $\quad \mathrm{pCR}=$ pathologic complete remission $\mathrm{RFS}=$ relapse-free survival; $\mathrm{ypTO} / \mathrm{is}$ ypNO/ $+=$ no residual invasive tumour in the breast; ypTO/is ypNO= no residual invasive tumour in breast and lymph nodes; ypTO ypNO= the absence of any tumour (invasive or non-invasive) in breast and lymph nodes.

${ }^{a} \mathrm{pCR}$, Fisher's exact test; RFS and Cox regression analysis.

pCR and RFS as end points (Table 5). Lower age was associated with a higher $\mathrm{pCR}$ rate (ypT0/is) $(10.2 \%$ vs $3.0 \%, P=0.044)$. The effect of age persisted when the end point was ypT0/is ypN0 but was no longer significant when the strictest pCR definition was 
used (ypT0 ypN0). The relapse-free survival was only affected by age, resulting in a worse prognosis when diagnosed over the age of 50 years (HR 3.5 (95\% CI: $1.5-8.3$ ), $P=0.004$ ). The use of surrogate intrinsic subtypes gave inconclusive results. The luminal $\mathrm{B}$ subtype based on grade was associated with a higher $\mathrm{pCR}$ rate (ypT0/is, $16.7 \%$ vs $4.6 \%, P=0.038$ ). There was no difference in relapse-free survival between surrogate intrinsic subtypes based on grade. Surrogate intrinsic subtypes based on Ki-67 resulted in a

\begin{tabular}{|c|c|c|c|c|}
\hline $\begin{array}{l}\text { MRI response } \\
\text { category }\end{array}$ & $\mathbf{N}$ & $\begin{array}{c}\text { Tumour } \\
\text { size } \\
\text { reduction } \\
\text { (\%) } \\
\text { Courses 1, } \\
2 \text { and } 3 \\
\text { MRI } 1 \text { vs } 2 \\
\text { (mean \%) }\end{array}$ & $\begin{array}{c}\text { Tumour } \\
\text { size } \\
\text { reduction } \\
\text { (\%) } \\
\text { Courses 4, } \\
5 \text { and } 6 \\
\text { MRI } 2 \text { vs } 3 \\
\text { (mean \%) }\end{array}$ & $\begin{array}{l}\text { Overall } \\
\text { tumour } \\
\text { size } \\
\text { reduction } \\
\text { (\%) } \\
\text { MRI } 1 \text { vs } 3 \\
\text { (mean \%) }\end{array}$ \\
\hline $\begin{array}{l}\text { Favourable } \\
(6 \times \text { ddAC) }\end{array}$ & 164 & 31 & $34^{a}$ & 56 \\
\hline $\begin{array}{l}\text { Unfavourable } \\
(3 \times \text { ddAC, } 3 \times D C)\end{array}$ & 82 & 12 & 27 & 35 \\
\hline \multicolumn{5}{|c|}{$\begin{array}{l}\text { Abbreviations: DC, docetaxel-capecitabine; ddAC = dose-dense doxorubicin and cyclo- } \\
\text { phosphamide; MRI = magnetic resonance imaging. Patients were evaluated by three MRIs; } \\
\text { MRI 1: baseline, before neoadjuvant chemotherapy, MRI 2: interim, after three courses of } \\
d d A C, M R I \text { : postchemotherapy, after three courses of ddAC or after three courses of DC. } \\
{ }^{a} \mathrm{~N}=157 \text { for the reduction percentage on MRI } 2 \text { vs } 3 \text { of favourable responders, because } \\
\text { seven patients had achieved a complete remission on MRI } 2 \text { and were not used for the } \\
\text { calculation of this percentage. }\end{array}$} \\
\hline
\end{tabular}

A

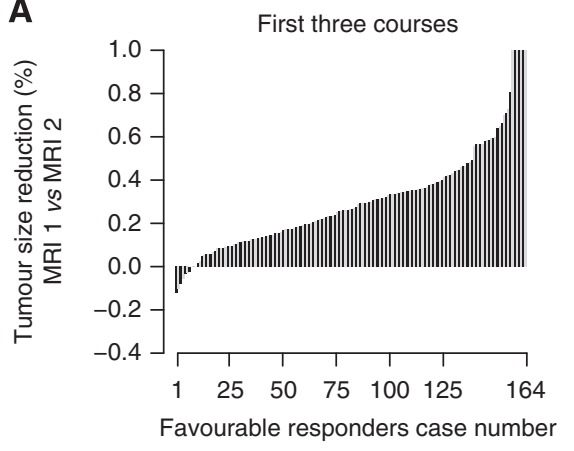

higher pCR rate (ypT0/is) for luminal B tumours $(P=0.056)$ but in a worse relapse-free survival rate (HR 2.8 (95\% CI: 1.0-8.1), $P=0.049)$.

Surrogate intrinsic subtypes. Tumours were classified as either surrogate luminal A or surrogate luminal B; the distinguishing feature between these was either the Ki-67 staining percentage or, alternatively, histological grade (I/II vs III) (Goldhirsch et al, 2011). The optimal Ki-67 cutoff point for differentiating the luminal A and luminal B surrogate intrinsic subtypes was determined in 60 tumour samples, of which both the Ki-67 percentage and the PAM50 intrinsic subtype definition (determined by mRNA expression microarray analysis) was available. Any cutoff point between 10 and $15 \%$ yielded essentially the same result and the usual cutoff of $14 \%$ was therefore used. Cohen's $\kappa$ was calculated to establish the degree of concordance between the two definitions of surrogate luminal A and luminal B vs the PAM50 classifier. The $\kappa$ values were 0.48 and 0.31 for $\mathrm{Ki}-67 \%$ and histological grade, respectively.

\section{DISCUSSION}

The use of adjuvant or neoadjuvant chemotherapy in ER+ HER2 - breast cancer ('luminal tumours') is challenging. It is clear that this subgroup of breast cancers includes tumours that are not responsive to chemotherapy (Goldhirsch et al, 2011) and even those that only infrequently achieve a pCR. As a group, however, the luminal subtype does derive benefit from (neo)adjuvant chemotherapy, including an important survival advantage (Peto et al, 2012). One strategy to improve the efficacy of chemotherapy
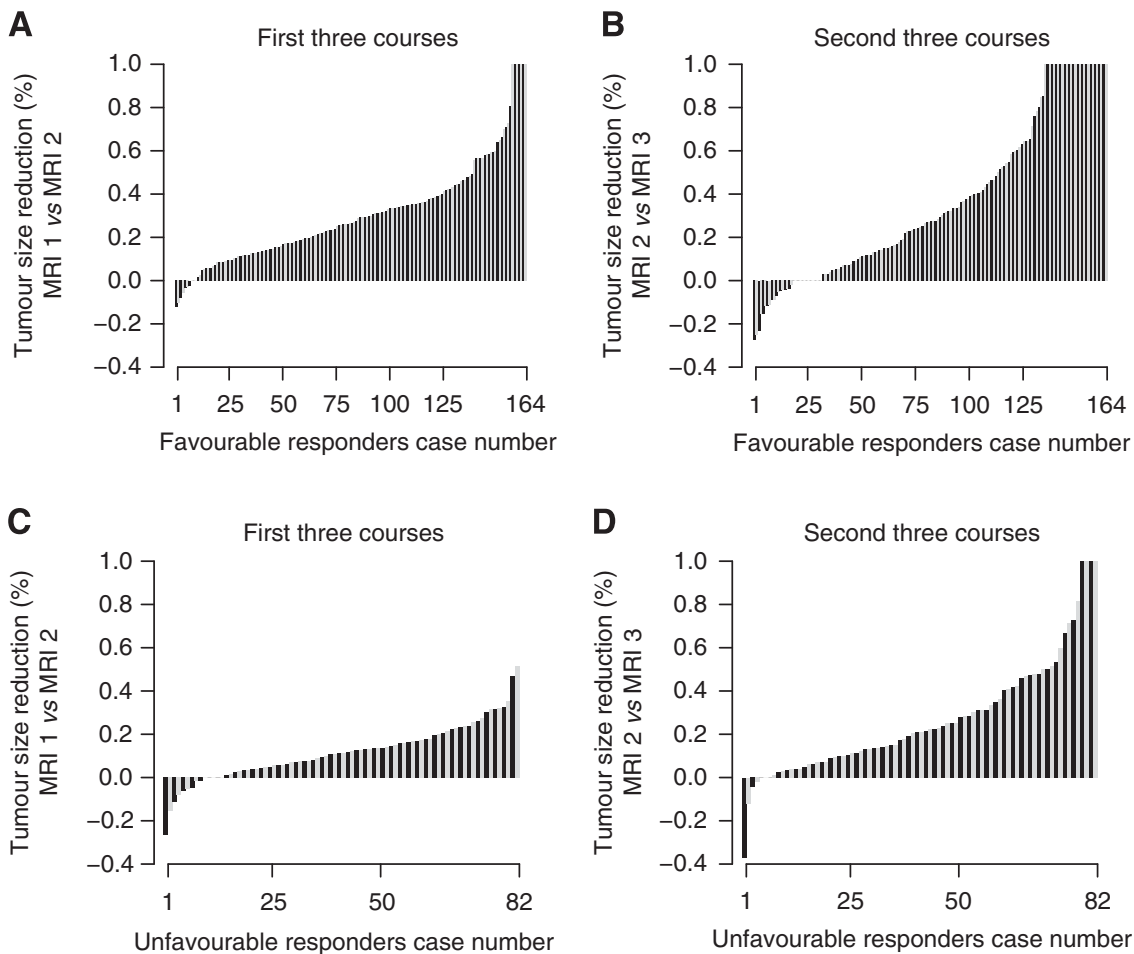

Figure 2. Waterfall plots of the MRI tumour size reductions before and after MRI response evaluation. Each bar represents one of the 246 patients who had three MRI measurements of the breast tumour (initial enhancement diameters). (A and B) Tumour size reduction in 164 favourable responders to the first three courses of $\operatorname{ddAC}(\mathbf{A})$, and to the second three courses of ddAC (B). (C and D) Tumour size reduction of 82 unfavourable responders to the first three courses of $\mathrm{dd} A C(\mathbf{C})$, and to the three courses of DC (D). The tumour size reductions after the first three courses are - by definition - smaller for the 'unfavourable responders' than for the 'favourable responders'. Over courses 4 through 6, after regimen adaptation in case of unfavourable response, the tumour size reductions are similar for the two response categories $(P=0.157)$. 


\begin{tabular}{|c|c|c|c|c|c|c|c|c|c|}
\hline Characteristic & $\mathbf{N}$ & $\begin{array}{c}\% \text { pCR } \\
\text { ypTo/is }\end{array}$ & $\boldsymbol{P}$-value & $\begin{array}{c}\% \text { pCR } \\
\text { ypTO/is ypNO }\end{array}$ & $\boldsymbol{P}$-value & $\begin{array}{c}\% \text { pCR ypT0 } \\
\text { ypNO }\end{array}$ & $\boldsymbol{P}$-value & $\begin{array}{c}\text { RFS hazard } \\
\text { ratio }(95 \% \mathrm{Cl})\end{array}$ & $\boldsymbol{P}$-value \\
\hline T-stage & & & 0.196 & & 0.681 & & 0.591 & & 0.447 \\
\hline $\begin{array}{l}\text { cT1/cT2 } \\
\text { cT3/cT4 }\end{array}$ & $\begin{array}{r}169 \\
77\end{array}$ & $\begin{array}{l}8.9 \\
3.9\end{array}$ & & $\begin{array}{l}2.4 \\
3.9\end{array}$ & & $\begin{array}{l}1.2 \\
2.6\end{array}$ & & $\begin{array}{c}1.0 \\
0.7(0.3-1.8)\end{array}$ & \\
\hline $\mathrm{N}$-stage & & & 1.0 & & 0.629 & & 1.0 & & 0.315 \\
\hline $\begin{array}{l}\mathrm{cN} \text { negative } \\
\mathrm{cN} \text { positive }\end{array}$ & $\begin{array}{r}49 \\
197\end{array}$ & $\begin{array}{l}6.1 \\
7.6\end{array}$ & & $\begin{array}{l}4.1 \\
2.5\end{array}$ & & $\begin{array}{l}2.0 \\
1.5\end{array}$ & & $\begin{array}{c}1.0 \\
1.9(0.6-6.3)\end{array}$ & \\
\hline Histology & & & 0.704 & & 1.0 & & 0.383 & & 0.906 \\
\hline $\begin{array}{l}\text { Lobular } \\
\text { Ductal }\end{array}$ & $\begin{array}{r}33 \\
190 \\
\end{array}$ & $\begin{array}{l}3.0 \\
7.4\end{array}$ & & $\begin{array}{l}3.0 \\
2.6\end{array}$ & & $\begin{array}{l}3.0 \\
1.1\end{array}$ & & $\begin{array}{c}0.9(0.3-3.1) \\
1.0\end{array}$ & \\
\hline Age (years) & & & 0.044 & & 0.044 & & 0.151 & & 0.004 \\
\hline $\begin{array}{l}<50 \\
\geqslant 50\end{array}$ & $\begin{array}{r}147 \\
99 \\
\end{array}$ & $\begin{array}{r}10.2 \\
3.0\end{array}$ & & $\begin{array}{l}4.8 \\
0.0\end{array}$ & & $\begin{array}{l}2.7 \\
0.0\end{array}$ & & $\begin{array}{c}1.0 \\
3.5(1.5-8.3)\end{array}$ & \\
\hline Endocrine responsiveness & & & 0.317 & & 1.0 & & 1.0 & & 0.686 \\
\hline $\begin{array}{l}\text { Incomplete } \\
\text { (ER or } P R<50 \%) \\
\text { High } \\
(\text { ER and } P R \geqslant 50 \%)\end{array}$ & $\begin{array}{l}109 \\
129\end{array}$ & $\begin{array}{l}9.2 \\
5.4\end{array}$ & & $\begin{array}{l}2.8 \\
2.3\end{array}$ & & $\begin{array}{l}0.9 \\
1.6\end{array}$ & & $\begin{array}{c}1.2(0.5-2.6) \\
1.0\end{array}$ & \\
\hline SIS (Ki-67) & & & 0.056 & & 0.329 & & 0.239 & & 0.049 \\
\hline $\begin{array}{l}\text { Luminal } A(<14) \\
\text { Luminal } B(\geqslant 14)\end{array}$ & $\begin{array}{r}128 \\
60\end{array}$ & $\begin{array}{r}3.9 \\
11.7\end{array}$ & & $\begin{array}{l}1.6 \\
5.0\end{array}$ & & $\begin{array}{l}0.8 \\
3.3\end{array}$ & & $\begin{array}{c}1.0 \\
2.8(1.0-8.1)\end{array}$ & \\
\hline SIS (grade) & & & 0.038 & & 0.115 & & 0.203 & & 0.992 \\
\hline $\begin{array}{l}\text { Luminal A (1/2) } \\
\text { Luminal B (3) }\end{array}$ & $\begin{array}{r}109 \\
30\end{array}$ & $\begin{array}{r}4.6 \\
16.7\end{array}$ & & $\begin{array}{r}2.8 \\
10.0\end{array}$ & & $\begin{array}{l}1.8 \\
6.7\end{array}$ & & $\begin{array}{c}1.0 \\
1.0(0.3-3.7)\end{array}$ & \\
\hline
\end{tabular}

could be, at least in theory, neoadjuvant chemotherapy with adaptation of the regimen to the response of the primary tumour.

We have reviewed our single-institution experience of neoadjuvant chemotherapy in ER + HER2 - tumours, unselected for (other) biological features. The treatment strategy consisted of initial chemotherapy with three courses of ddAC with a response adapted approach; if a satisfactory response was achieved, as defined by at least a $25 \%$ decrease of the late enhancement diameter on MRI, the ddAC was continued to a total of six courses. If not, the treatment plan was changed to three courses of DC, a combination of a taxane and an antimetabolite (docetaxel and capecitabine). A total of 309 patients was started on this approach and 246 patients were evaluated by three serial MRIs. Here, we describe the efficacy of this strategy in relation to the characteristics of the primary tumours.

Our neoadjuvant program has a non-randomised design, with the primary objectives to develop tests that are predictive of response and to refine the techniques to monitor response during treatment. Contrast-enhanced MRI, although the best imaging method currently available to evaluate primary breast cancer (Yeh et al, 2005; Shin et al, 2011) was shown not to be a very reliable predictor of pathologic response (Loo et al, 2011). Nevertheless, an 'unfavourable response' on the interim MRI was associated with a lower rate of pCR of the breast (ypT0/is) (Table 3). For other pCR definitions and for relapse-free survival, the results in the initially favourable responder group were similar to those of the initially unfavourable responder group, which switched to the presumably non-cross-resistant regimen.

The validity of this adaptive strategy cannot be established from our non-controlled study, but some support for the concept has been presented in a recent analysis of the German Breast Group (von Minckwitz et al, 2013). We did, however, obtain serial MRI measurements before the initiation of chemotherapy, and also after three and six courses. If the switch to a docetaxel-based regimen in unfavourably responding patients would indeed be effective, one would expect more shrinkage of the tumour between the interim and postchemotherapy MRI in this group than had been observed between the baseline and the interim MRI. This is indeed what was found (Table 4 and Figure 2).

Unsurprisingly, the reduction in diameter of the breast tumour at initial enhancement after the first three courses of ddAC was less $(12 \%)$ in the unfavourably responding patients than in the responding ones (31\%), as the 'unfavourable' group was defined by a closely related MRI parameter, the reduction in diameter of the tumour at late enhancement. The second set of three courses, however, led to $27 \%$ shrinkage in the previously unfavourably responding patients, which is comparable to the initial shrinkage in favourable responders (31\%) and the second set of three courses in the initially favourable responders (34\%). Apparently, DC was able to induce a satisfactory response, when ddAC was not (Figure 2). The average total percentage of tumour shrinkage remained lower in the initially unfavourable responders (35\%) than in the favourable responders (56\%), despite the efficacy of the alternative chemotherapy regimen. This could very well be the result of having received only three effective courses of chemotherapy, whereas the (initially) favourable responders had received six effective courses, with a percentage of tumour shrinkage during the second set of three courses (34\%) that was similar to that of courses 1 through 3 (31\%). If this explanation is correct, one might consider extending the DC therapy in initially unfavourable responders to six rather than three courses, to obtain a similar total reduction in tumour size. Evaluation of such a strategy will require randomised studies.

Alternative explanations for the apparent efficacy of the adaptive strategy are, of course, conceivable. For example, some 
tumours (perhaps slowly proliferating ones) could require more time than others to shrink in size but could, given time, eventually achieve the same reduction in size as more rapidly responding ones. This could be an alternative explanation for the data in Table 2. We have, however, found very few differences between the tumours with favourable and unfavourable responses after three courses of ddAC (Table 2). In contrast to what one might expect, unfavourable response tumours did not contain more low-grade or 'highly endocrine-responsive' tumours. There was no prognostic impact of the early responsiveness, although such an effect could possibly have been obscured by the administration of additional, postsurgical adjuvant chemotherapy. However, the percentage of patients receiving additional chemotherapy was equal in the two response categories: $14(17 \%)$ of the 82 unfavourable responders and $29(18 \%)$ of the 164 favourable responders.

For the whole group, the neoadjuvant chemotherapy regimen and strategy performed close to what one would expect based on the results of others. For instance, the predicted pCR percentage was consistent with the prediction by the nomogram published by Colleoni et al (2010). This model is based on three characteristics of the tumour, the percentage of ER, PR and Ki-67, and the number of chemotherapy courses administered.

An important question is how the adaptation strategy could be optimised. First of all, the methods to monitor response need refining. Magnetic resonance imaging results are unreliable to predict pCR in this subgroup (Loo et al, 2011). Recently published data from our group (Koolen et al, 2013) and from others suggest that the addition of or combination with PET/CT could improve the accuracy of the response evaluation (Tateishi et al, 2012). In addition, more appropriate outcome measures than PCR should be defined for 'luminal' tumours, that can be assessed in a replicable manner after the completion of local treatment, and that correlate robustly with relapse-free survival. Even if the pCR, regardless of its definition, would be predictive of survival, the rate of occurrence is so low that it would be of little use in ER + HER2 - breast cancer.

In conclusion, this analysis of a series of consecutive patients who underwent neoadjuvant chemotherapy using a responseadapted chemotherapy approach suggests that a change in chemotherapy regimen may still be effective when the initial chemotherapy is not. It thereby supports an analysis of the cumulative data from the German Breast Group that suggested a survival advantage for a switch of chemotherapy regimen in nonresponding patients. If correct, a response adaptive chemotherapy selection in the neoadjuvant setting might further improve the cure rate of patients with larger breast cancers, underscoring the need for controlled trials of this approach.

\section{ACKNOWLEDGEMENTS}

We thank Anita Paape, Marjo Holtkamp and Margaret Schot for their contribution to this study. A part of this study was performed within the framework of CTMM, the Center for Translational and Molecular Medicine (http: //www.ctmm.nl), project Breast CARE (grant no. 03O-104).

\section{CONFLICT OF INTEREST}

The authors declare no conflict of interest.

\section{REFERENCES}

Colleoni M, Bagnardi V, Rotmensz N, Gelber RD, Viale G, Pruneri G, Veronesi P, Torrisi R, Cardillo A, Montagna E, Campagnoli E, Luini A,
Intra M, Galimberti V, Scarano E, Peruzzotti G, Goldhirsch A (2009) Increasing steroid hormone receptors expression defines breast cancer subtypes non responsive to preoperative chemotherapy. Breast Cancer Res Treat 116: 359-369.

Colleoni M, Bagnardi V, Rotmensz N, Viale G, Mastropasqua M, Veronesi P, Cardillo A, Torrisi R, Luini A, Goldhirsch A (2010) A nomogram based on the expression of Ki-67, steroid hormone receptors status and number of chemotherapy courses to predict pathological complete remission after preoperative chemotherapy for breast cancer. Eur J Cancer 46: 2216-2224.

Ellis IO, Galea M, Broughton N, Locker A, Blamey RW, Elston CW (1992) Pathological prognostic factors in breast cancer. II. Histological type. Relationship with survival in a large study with long-term follow-up. Histopathology 20: 479-489.

Goldhirsch A, Wood WC, Coates AS, Gelber RD, Thurlimann B, Senn HJ (2011) Strategies for subtypes - dealing with the diversity of breast cancer: highlights of the St. Gallen International Expert Consensus on the Primary Therapy of Early Breast Cancer 2011. Ann Oncol 22: 1736-1747.

Koolen BB, Pengel KE, Wesseling J, Vogel WV, Vrancken Peeters MJ, Vincent AD, Gilhuijs KG, Rodenhuis S, Rutgers EJ, Valdes Olmos RA (2013) FDG PET/CT during neoadjuvant chemotherapy may predict response in ER-positive/HER2-negative and triple negative, but not in HER2-positive breast cancer. Breast 22: 691-697.

Loo CE, Straver ME, Rodenhuis S, Muller SH, Wesseling J, Vrancken Peeters MJ, Gilhuijs KG (2011) Magnetic resonance imaging response monitoring of breast cancer during neoadjuvant chemotherapy: relevance of breast cancer subtype. J Clin Oncol 29: 660-666.

Loo CE, Teertstra HJ, Rodenhuis S, van de Vijver MJ, Hannemann J, Muller SH, Peeters MJ, Gilhuijs KG (2008) Dynamic contrast-enhanced MRI for prediction of breast cancer response to neoadjuvant chemotherapy: initial results. Am J Roentgenol 191: 1331-1338.

Lips EH, Mulder L, de Ronde JJ, Mandjes IA, Vincent A, Vrancken Peeters MT, Nederlof PM, Wesseling J, Rodenhuis S (2012) Neoadjuvant chemotherapy in ER + HER2 - breast cancer: response prediction based on immunohistochemical and molecular characteristics. Breast Cancer Res Treat 131: 827-836.

Mauri D, Pavlidis N, Ioannidis JP (2005) Neoadjuvant versus adjuvant systemic treatment in breast cancer: a meta-analysis. J Natl Cancer Inst 97: 188-194.

Parker JS, Mullins M, Cheang MC, Leung S, Voduc D, Vickery T, Davies S, Fauron C, He X, Hu Z, Quackenbush JF, Stijleman IJ, Palazzo J, Marron JS, Nobel AB, Mardis E, Nielsen TO, Ellis MJ, Perou CM, Bernard PS (2009) Supervised risk predictor of breast cancer based on intrinsic subtypes. J Clin Oncol 27: 1160-1167.

Peto R, Davies C, Godwin J, Gray R, Pan HC, Clarke M, Cutter D, Darby S, McGale P, Taylor C, Wang YC, Bergh J, Di Leo A, Albain K, Swain S, Piccart M, Pritchard K (2012) Comparisons between different polychemotherapy regimens for early breast cancer: meta-analyses of long-term outcome among 100000 women in 123 randomised trials. Lancet 379: 432-444.

Prati R, Minami CA, Gornbein JA, Debruhl N, Chung D, Chang HR (2009) Accuracy of clinical evaluation of locally advanced breast cancer in patients receiving neoadjuvant chemotherapy. Cancer 115: 1194-1202.

Rodenhuis S, Mandjes IA, Wesseling J, van de Vijver MJ, Peeters MJ, Sonke GS, Linn SC (2010) A simple system for grading the response of breast cancer to neoadjuvant chemotherapy. Ann Oncol 21: 481-487.

Rosen EL, Blackwell KL, Baker JA, Soo MS, Bentley RC, Yu D, Samulski TV, Dewhirst MW (2003) Accuracy of MRI in the detection of residual breast cancer after neoadjuvant chemotherapy. Am J Roentgenol 181: $1275-1282$.

Shin HJ, Kim HH, Ahn JH, Kim SB, Jung KH, Gong G, Son BH, Ahn SH (2011) Comparison of mammography, sonography, MRI and clinical examination in patients with locally advanced or inflammatory breast cancer who underwent neoadjuvant chemotherapy. Br J Radiol 84: 612-620.

Smith IC, Heys SD, Hutcheon AW, Miller ID, Payne S, Gilbert FJ, Ah-See AK, Eremin O, Walker LG, Sarkar TK, Eggleton SP, Ogston KN (2002) Neoadjuvant chemotherapy in breast cancer: significantly enhanced response with docetaxel. J Clin Oncol 20: 1456-1466.

Tateishi U, Miyake M, Nagaoka T, Terauchi T, Kubota K, Kinoshita T, Daisaki H, Macapinlac HA (2012) Neoadjuvant chemotherapy in breast cancer: prediction of pathologic response with PET/CT and dynamic contrast-enhanced MR imaging - prospective assessment. Radiology 263: 53-63. 
von Minckwitz G, Untch M, Blohmer JU, Costa SD, Eidtmann H, Fasching PA, Gerber B, Eiermann W, Hilfrich J, Huober J, Jackisch C, Kaufmann M, Konecny GE, Denkert C, Nekljudova V, Mehta K, Loibl S (2012) Definition and impact of pathologic complete response on prognosis after neoadjuvant chemotherapy in various intrinsic breast cancer subtypes. J Clin Oncol 30: 1796-1804.

von Minckwitz G, Untch M, Loibl S (2013) Update on neoadjuvant/ preoperative therapy of breast cancer: experiences from the German Breast Group. Curr Opin Obstet Gynecol 25: 66-73.

Yeh E, Slanetz P, Kopans DB, Rafferty E, Georgian-Smith D, Moy L, Halpern E, Moore R, Kuter I, Taghian A (2005) Prospective comparison of mammography, sonography, and MRI in patients undergoing neoadjuvant chemotherapy for palpable breast cancer. Am J Roentgenol 184: $868-877$.

This work is published under the standard license to publish agreement. After 12 months the work will become freely available and the license terms will switch to a Creative Commons AttributionNonCommercial-Share Alike 3.0 Unported License. 